\title{
Evaluation of Hydraulic Energy Nozzle Suitable for Low Velocity Air-Assisted Sprayer
}

\author{
S. Syed Imran ${ }^{1 *}$ and A. Surendrakumar ${ }^{2}$ \\ ${ }^{1}$ Agricultural Mechanization Division, Central Institute of Agricultural Engineering, \\ Bhopal, India \\ ${ }^{2}$ Agricultural Machinery Research Centre, Tamil Nadu Agricultural University, \\ Coimbatore, India \\ *Corresponding author
}

\section{A B S T R A C T}

\section{Keywords}

Air-assisted, Droplet size, Hydraulic nozzle, Knapsack sprayer, Pesticide

Article Info

Accepted:

12 December 2017

Available Online:

10 January 2018
Performance evaluation of commercially available hydraulic energy nozzles (HCN/PB, $\mathrm{HCN} / \mathrm{PC}, \mathrm{HCN} / \mathrm{PD}$ and $\mathrm{HCN} / \mathrm{PE}$ ) used in manually operated sprayer was conducted to identify the suitable nozzle for low velocity air-assisted sprayer. The discharge rate, droplet size, droplet size distribution pattern and spray distribution pattern of all the types of nozzles were measured with a pressure range of 0.1 to $0.4 \mathrm{MPa}$ at an interval of 0.1 $\mathrm{MPa}$. It was found that with the increase in pressure from 0.1 to $0.4 \mathrm{MPa}$, the discharge rate, swath width and spray angle increased for all the four types of nozzles. At all working pressures, the discharge rate and spray width is higher for HCN/PE nozzle followed by $\mathrm{HCN} / \mathrm{PD}, \mathrm{HCN} / \mathrm{PC}$ and HCN/PB. The discharge rate of HCN/PB nozzle (363 to 533 $\mathrm{ml} / \mathrm{min}$ ) was found suitable for cotton crop. For the tested pressure range (0.1 to $0.4 \mathrm{MPa})$, the HCN/PB nozzle produces best droplet size in between 100 to $150 \mu \mathrm{m}$, good uniformity coefficient and the maximum percentage $(63.81,64.65,61.56$ and 65.5 per cent) of volume of the droplets at 100 to $200 \mu \mathrm{m}$.

\section{Introduction}

Plant protection plays a significant role in increasing the productivity of the crop. Insect pests, diseases and weeds inflict enormous losses to the potential agricultural production. Pests and diseases cause 62 per cent of total annual crop losses in India. The effective pesticide application gives good pest control and increases food productivity. Pesticides applications are dispersed mostly by knapsack operated hydraulic energy nozzle sprayers. However farmers are not satisfied with the results of these sprayers due to insufficient control of pest at the bottom of the crop canopy and underside of leaves surface.

In the recent years, an air-assisted sprayer developed shows a promising result with good crop coverage and deposit on the underside of leaves. Hence, an evaluation study was undertaken to identify the most suitable hydraulic energy nozzle for low velocity airassisted sprayer in term of proper discharge rate, spray droplet size and spray distribution pattern. Thus, it will help the farmers to 
reduce the wastage of chemicals along with effective control of pests and diseases.

Earlier, the performance of commercially available hydraulic energy nozzle (NMD/S, BAN, Broad cone, NMM, NTM) was studied for suitability in orchard spraying with a pressure range of 1.5 to $3 \mathrm{MPa}$ at an interval of $0.5 \mathrm{MPa}$ and found that the discharge rate of all nozzles increased with increasing pressure (Senthilkumar and Kumar, 2007). The spray distribution pattern of three nozzles i.e. Triple Action Nozzle (TAN), Bi-Action Nozzle (BAN) and Hollow Cone Nozzle (HCN) at four different pressures of $0.25,0.3$, 0.35 and $0.4 \mathrm{MPa}$ was reported by Singh (2006) and found that swath width, spray angle and discharge rate increased for all the three types of nozzles with increase in pressure from 0.25 to $0.4 \mathrm{MPa}$. Methylene blue solution was used as the dye solution to determine the droplet size by collecting the droplet deposition at different spray pressure on white photographic paper Jayashree (2013). The study showed that the droplet size decreases from 153.32 to $106.28 \mu$ with increases in pressure from 0.15 to $0.35 \mathrm{MPa}$

A spray patternator was developed to test spray pattern of agricultural spray nozzles with $1640 \times 1200 \mathrm{~mm}$ size, which had 55 numbers of triangular shaped channels each of $25 \mathrm{~mm}$ wide (Tajuddin, 1995). The patternator has the provision of a tilting tube rack to hold 55 graduated glass tubes of $25 \mathrm{~mm}$ bore and $200 \mathrm{cc}$ capacities. He reported that the developed spray patternator was satisfactory to get spray distribution pattern of a hollow cone nozzle. Giles and Camino (1990) analyzed the spray pattern characteristics of an electronic flow controller for flat fan, hollow cone and solid cone spray nozzles. The results showed that as the flow rate was reduced, spray deposition was concentrated in the region underneath the nozzle and reduced in the outer regions of the spray pattern.

\section{Materials and Methods}

\section{Selection of nozzle}

Hollow cone nozzle was selected because it is a very popular type of hydraulic nozzle for spraying insecticides and fungicide. Hollow cone nozzles are good for treating complex targets because spray particles move in infinite angles and various planes providing better penetration of spray. The variation of liquid pressure can vary discharge rate, droplet size and spray distribution pattern. A four commercially available hollow cone nozzle were used to study the spray characteristics at different pressure

Aspee 80450

Aspee 100700

Aspee 1001000

Aspee 1001350

\section{Measurement of discharge rate}

The discharge rate of the selected nozzle was tested for the pressure range of 0.1 to $0.4 \mathrm{MPa}$ at an interval of $0.1 \mathrm{MPa}$. The discharge liquid was collected for a period of 1 minute in a measuring jar of 1.51 capacity. The total volume of water was measured and discharge rate was calculated.

\section{Measurement of droplet size}

The most widely used parameters to represent droplet size are the volume median diameter (VMD) measured in micro meters $(\mu \mathrm{m})$ and the relative span. The spray is coloured with water soluble methylene blue of $0.75 \%$ concentration. Droplets are collected on photographic paper of $25 \times 25 \mathrm{~mm}$ under pressure range of 0.1 to $0.4 \mathrm{MPa}$ at an interval of $0.1 \mathrm{MPa}$. These samples were kept for dry to avoid distortion to the droplets. The droplets size in photographic paper was captured with a microscope equipped with an 
ocular reticule. The scanned images were analyzed using Deposit Scan software. The spread factor of the spray droplets on the photographic paper was calculated as 1.5.

\section{Measurement of spray distribution pattern}

The standard spray patternator having 55 numbers of channels with size $25 \mathrm{~mm}$ wide and $1000 \mathrm{~mm}$ length was used for study the spray width, spray angle and spray distribution pattern of selected commercial nozzles. Each nozzle was mounted at a height of $45 \mathrm{~cm}$ above the patternator in such a way that the axis of spray was at right angle to the horizontal. At the pressure settings of 0.1, 0.2, 0.3 and $0.4 \mathrm{MPa}$, sprayed liquid was collected in the glass tubes for five minute and the volume of collected liquid from each channel of patternator was noted. The number of channels with sprayer liquid was used for calculating spray width and spray angle.

\section{Results and Discussion}

\section{Effect of pressure on discharge rate}

The discharge rate for all types of nozzles was directly proportional to pressure. Irrespective of pressure $\mathrm{HCN} / \mathrm{PE}$ recorded maximum discharge rate of $810 \mathrm{ml} / \mathrm{min}$ to $1560 \mathrm{ml} / \mathrm{min}$ followed by HCN/PD nozzle (710 to 1080 $\mathrm{ml} / \mathrm{min}$ ), HCN/PC nozzle (580 to $870 \mathrm{ml} / \mathrm{min}$ ), HCN/PB nozzle (363 to $533 \mathrm{ml} / \mathrm{min}$ ) (Figure 1). For all the nozzles discharge rate gradually increase with increase in pressure.

\section{Effect of pressure on droplet size}

Droplet size was measured with the volume mean diameter (VMD) and relative span for the test nozzles.

The droplet size for all types of nozzles was inversely proportional to pressure. The droplet size gradually decreases with increase in pressure for all the nozzle. The VMD of $\mathrm{HCN} / \mathrm{PB}$ is minimum at all pressure varied from $0.1,0.2,0.3,0.4 \mathrm{MPa}$ and it was found $148.5,128.9,111.5,101.2 \mu \mathrm{m}$ followed by $\mathrm{HCN} / \mathrm{PC}$ was $166.5,154.2,139.2,123.3 \mu \mathrm{m}$, HCN/PD was 172.8, 164.5, 152.3, $132.1 \mu \mathrm{m}$ and $\mathrm{HCN} / \mathrm{PE}$ was $186.2,179.8,175$ and 149.5 $\mu \mathrm{m}$ (Figure 2). If VMD is within the range of 101 to $200 \mu \mathrm{m}$ it is classified as fine spray as per the classification given by Thronhill and Mathews (1995). All of the tested nozzles fall under fine droplets category. The droplets size of 100 to $150 \mu \mathrm{m}$ diameter was found sufficiently close to give a high probability of a direct hit on small insects Johnstone (1972). Hence the nozzle HCN/PB has been best to spray in insecticide and fungicide application.

\section{Effect of pressure on uniform coefficient}

For uniform coefficient of droplet size distribution can be identified by relative span, it should be close to unity. The uniformity coefficient of the nozzle $\mathrm{HCN} / \mathrm{PB}$ was found best followed by $\mathrm{HCN} / \mathrm{PD}, \mathrm{HCN} / \mathrm{PC}$ and HCN/PE (Figure 3).

\section{Effect of pressure on droplet size distribution}

The tested nozzles do not have any regular pattern in the percentage of volume of droplets at 100 to $200 \mu \mathrm{m}$ except nozzle HCN/PC. The nozzle $\mathrm{HCN} / \mathrm{PC}$ observed that the percentage of volume of droplets at 100 to $200 \mu \mathrm{m}$ decreases with increase in pressure.

The maximum percentage of volume of droplets at 100 to $200 \mu \mathrm{m}$ is observed for $\mathrm{HCN} / \mathrm{PB}$ nozzle $(69 \%$ at $0.3 \mathrm{MPa})$, followed by $\mathrm{HCN} / \mathrm{PC}$ nozzle $(50.7 \%$ at $0.1 \mathrm{MPa})$, $\mathrm{HCN} / \mathrm{PE}$ nozzle $(50.5 \%$ at $0.1 \mathrm{MPa})$ and $\mathrm{HCN} / \mathrm{PD}$ nozzle $(46.47 \%$ at $0.2 \mathrm{MPa})$. Irrespective of pressure $\mathrm{HCN} / \mathrm{PB}$ has highest percentage of volume of droplet at 100 to 200 $\mu \mathrm{m}$ (Figure 4). 
Fig.1 Spray discharge rate of different nozzle at varying pressure

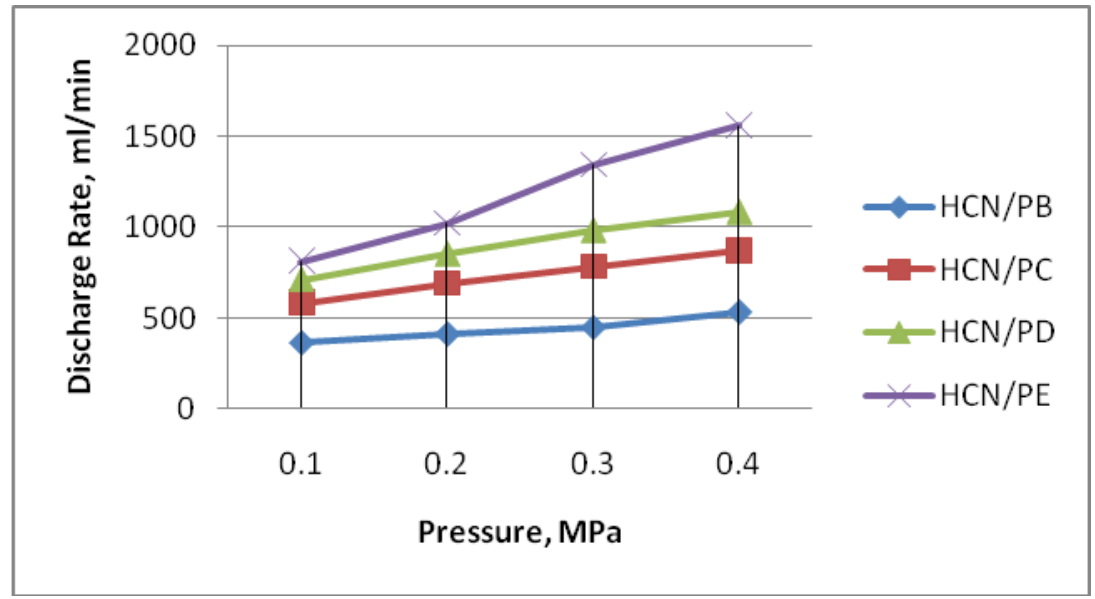

Fig.2 Effect of pressure on droplet size at different nozzles

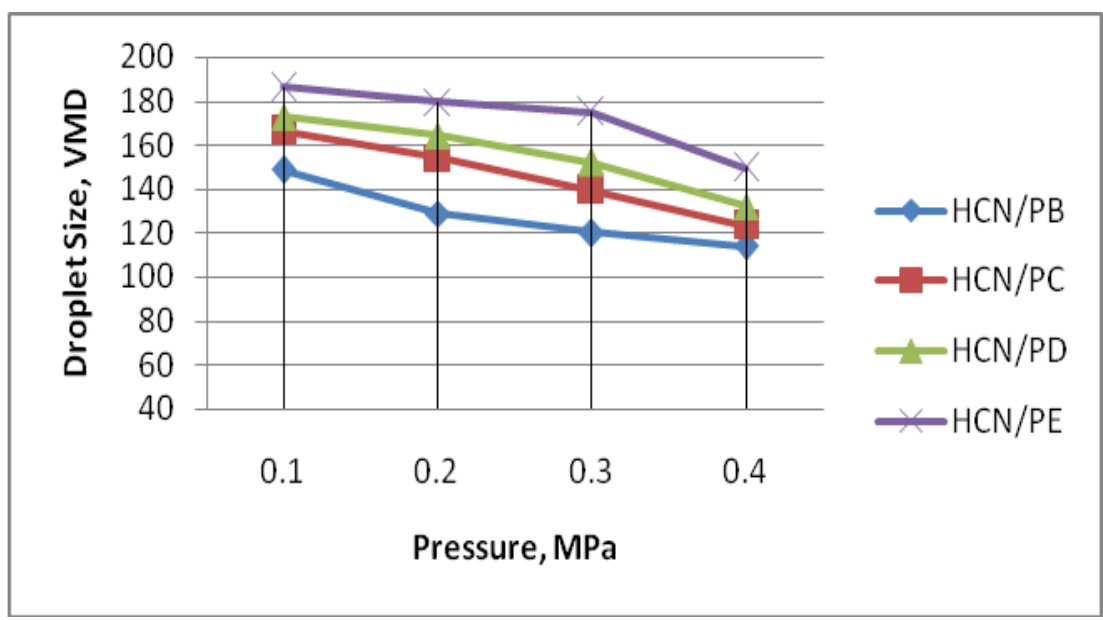

Fig.3 Effect of pressure on relative span of droplets from various nozzles

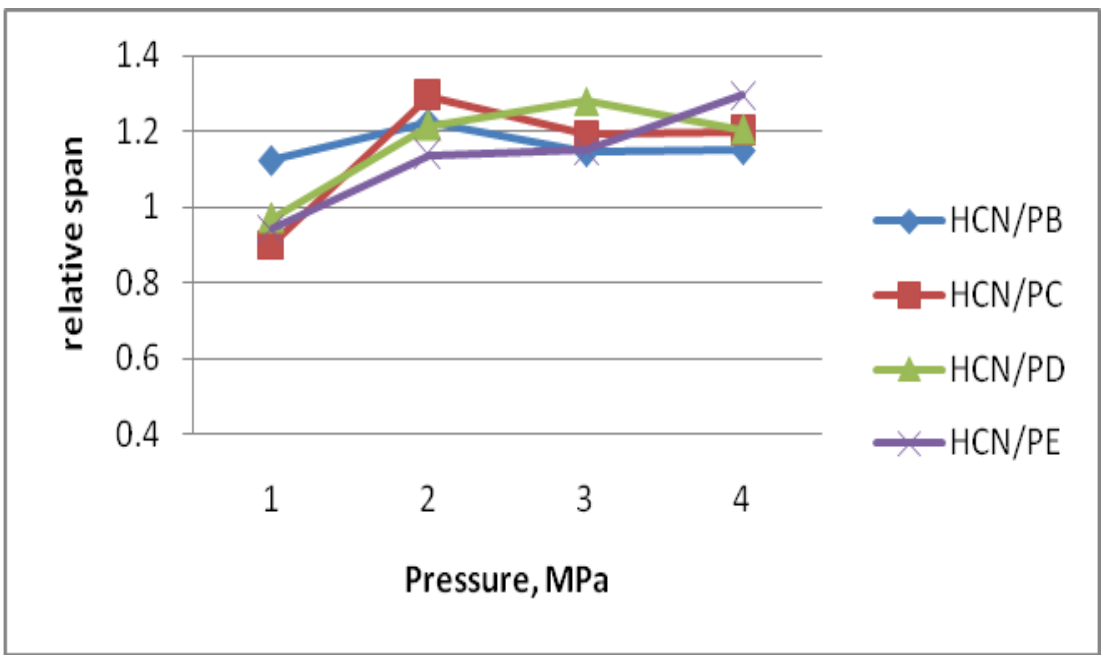


Fig.4 Droplet size distribution of HCN/PB, HCN/PC, HCN/PD and HCN/PE nozzles at varying pressures
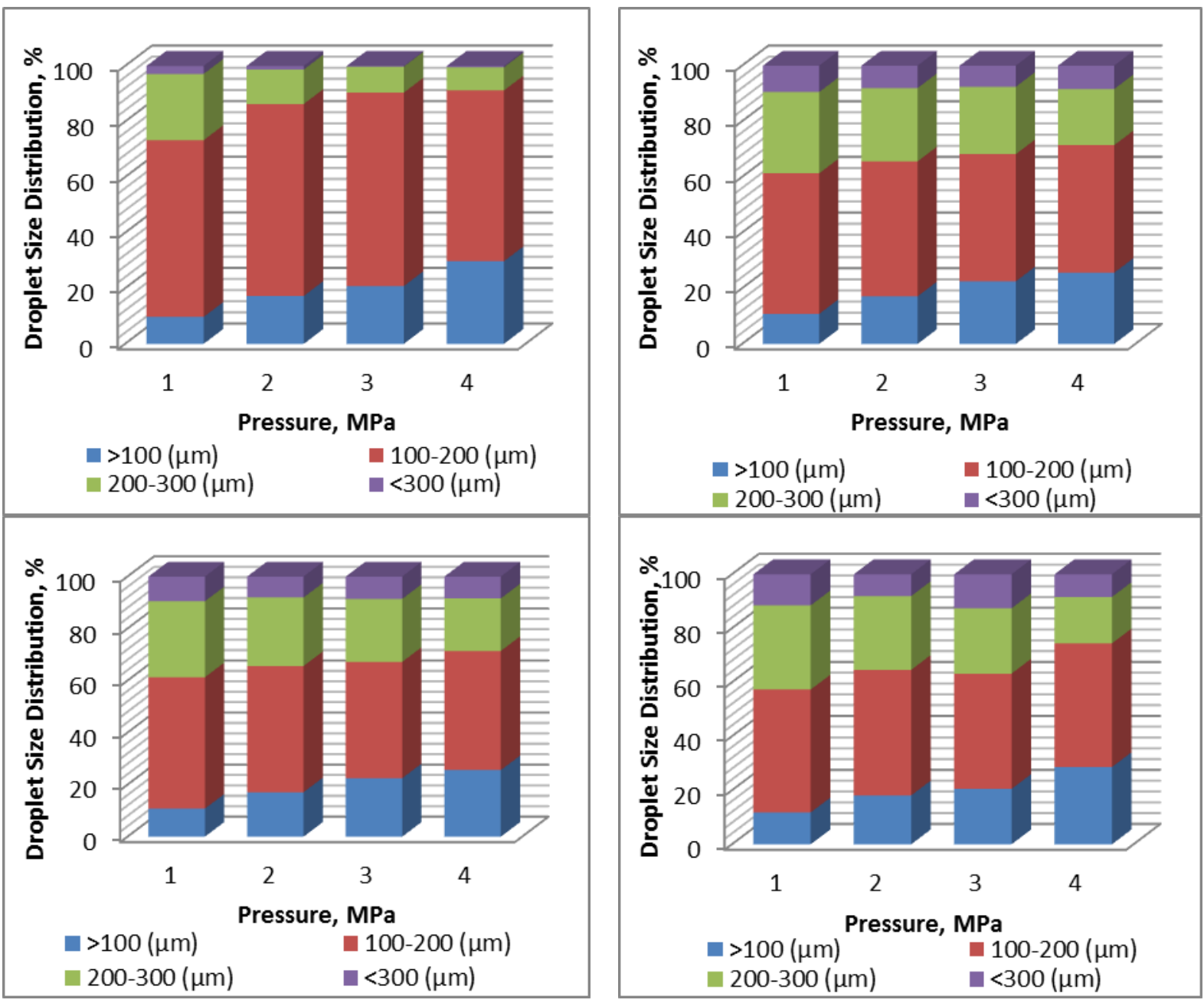

Fig.5 Spray width and spray angle of HCN/PB, HCN/PC, HCN/PD and HCN/PE nozzles at varying pressures
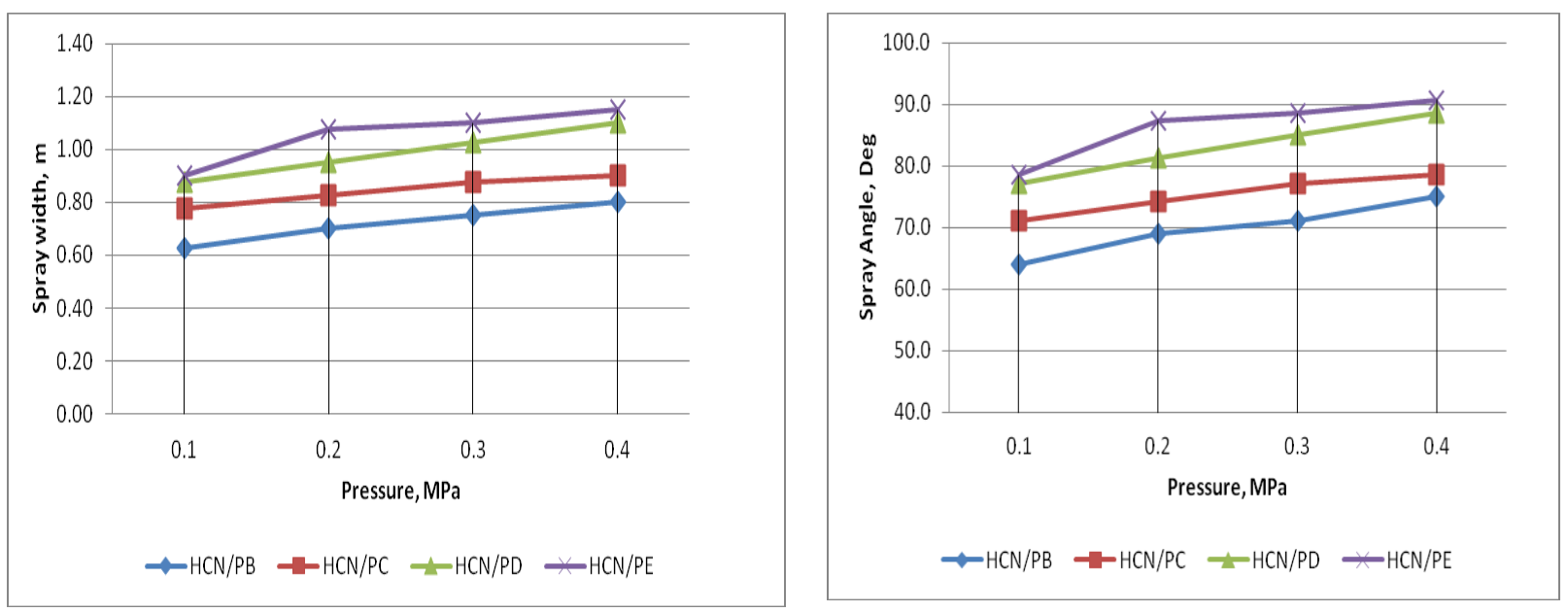
Fig.6a Spray distribution of $\mathrm{HCN} / \mathrm{PB}$ at different pressure

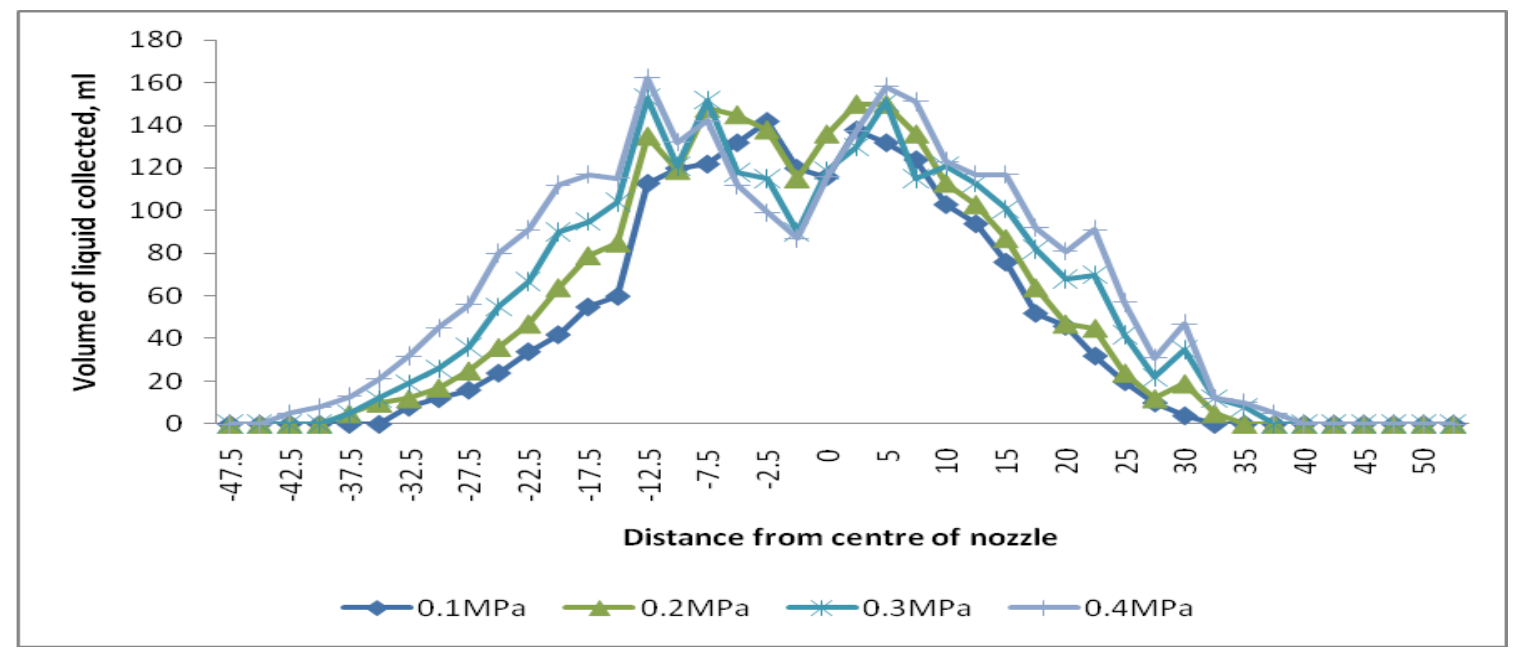

Fig.6b Spray distribution of $\mathrm{HCN}$ / PC at different pressure

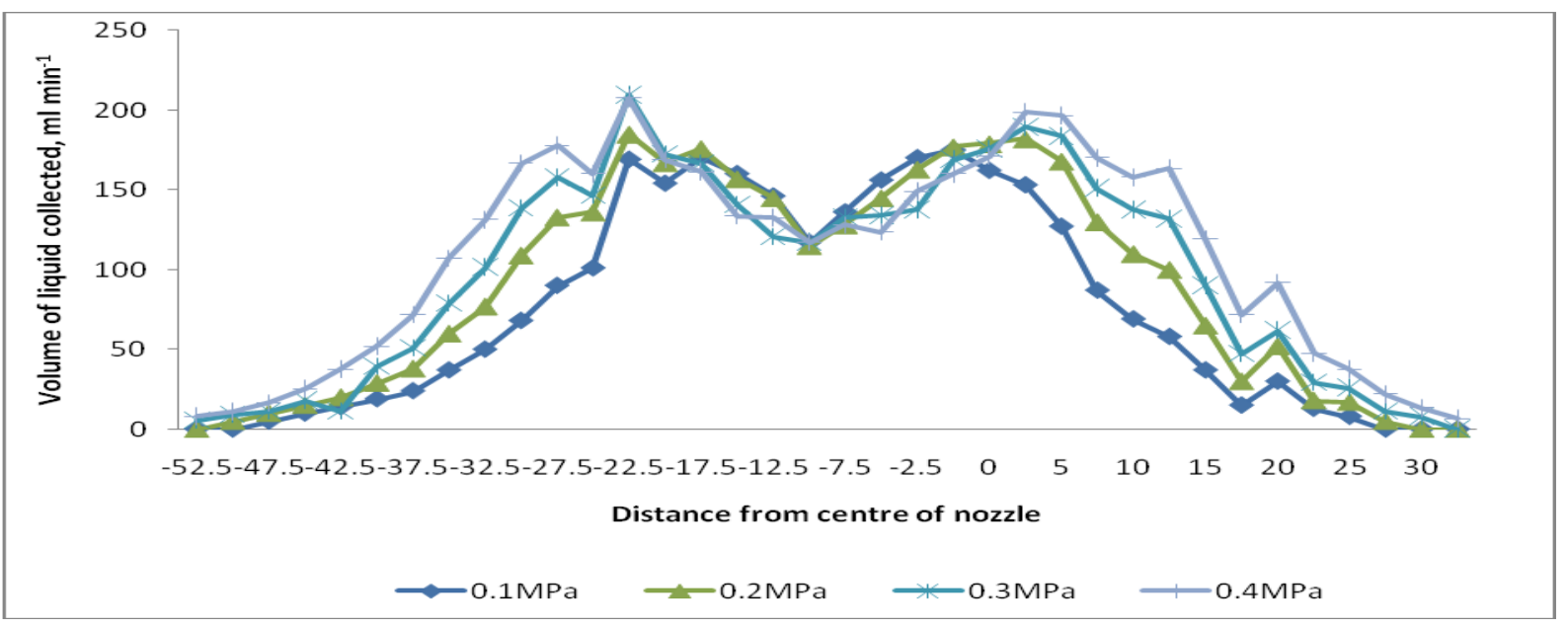

Fig.6c Spray distribution of HCN / PD at different pressure

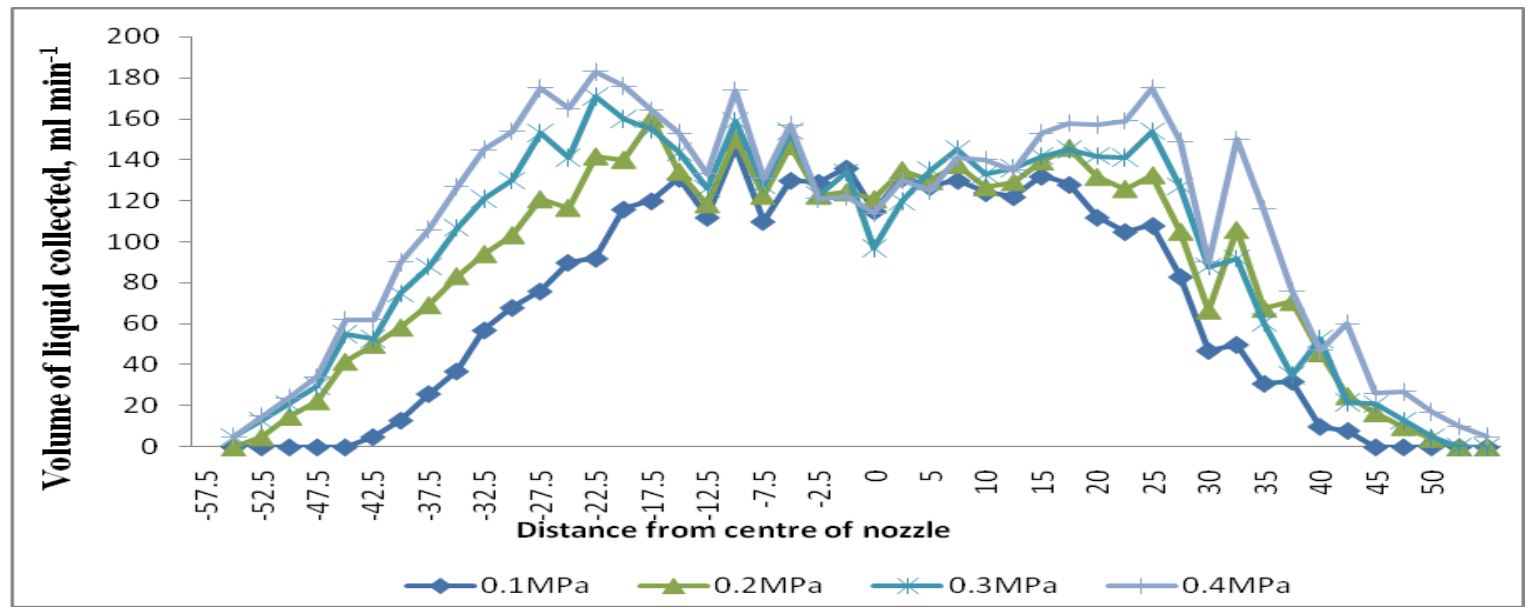


Fig.6d Spray distribution of $\mathrm{HCN} / \mathrm{PE}$ at different pressure

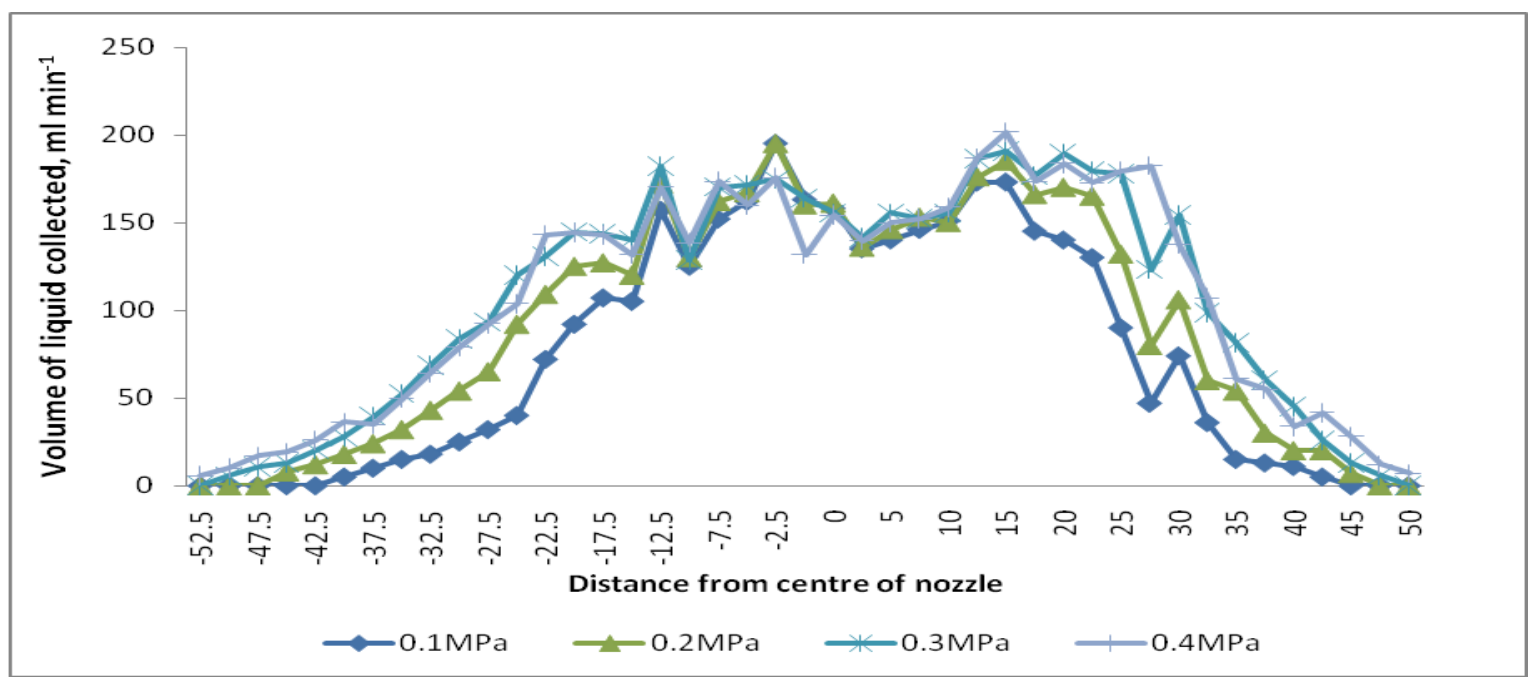

Effect of pressure on spray angle and spray width

The standard spray patternator was used to calculate the swath width and spray angle of the tested nozzles. The nozzle HCN/PB, $\mathrm{HCN} / \mathrm{PC}, \mathrm{HCN} / \mathrm{PD}$ and HCN/PE swath width was increased from 0.63 to $0.8 \mathrm{~m}, 0.78$ to $0.9 \mathrm{~m}, \quad 0.88$ to 1.1 and 0.90 to $1.15 \mathrm{~m}$ respectively, with increase in working pressure from $0.1 \mathrm{MPa}$ to $0.4 \mathrm{MPa}$ (Figure 5). The highest swath width was observed for $\mathrm{HCN} / \mathrm{PE}$ followed by HCN/PD, HCN/PC and lowest was $\mathrm{HCN} / \mathrm{PB}$. The spray angle was increased 64 to $75^{\circ}, 71.1$ to $78.5^{\circ}, 77.1$ to $88.5^{\circ}, 78.5$ to $90.7^{\circ}$ respectively for nozzles $\mathrm{HCN} / \mathrm{PB}, \mathrm{HCN} / \mathrm{PC}, \mathrm{HCN} / \mathrm{PD}$ and $\mathrm{HCN} / \mathrm{PE}$, with increase in working pressure from $0.1 \mathrm{MPa}$ to $0.4 \mathrm{MPa}$. The highest swath width was observed for $\mathrm{HCN} / \mathrm{PE}$ and lowest was $\mathrm{HCN} / \mathrm{PB}$.

\section{Effect of pressure on spray distribution pattern}

As the pressure increased, the volume of spray deposition outer position of the each channel was increased and central position of the patternator was decreased. The same result was found for the entire tested nozzle.
The coefficient of variation in the spray distribution of a HCN/PB nozzle was 63.81, 64.65, 61.56 and 65.5 per cent, HCN/PC was 75.3, 78.4, 76.4 and 78.5 per cent, HCN/PD was $69.16,72.56,71.9$ and $74.36, \mathrm{HCN} / \mathrm{PE}$ was $79.9,81.95,78.34$ and 82.26 at the pressures of $0.1,0.2,0.3$ and $0.4 \mathrm{MPa}$, respectively (Figure 6 A-D). The coefficient of variation in spray distribution was lowest for $\mathrm{HCN} / \mathrm{PB}$ nozzle as compared other nozzles. The HCN/PB nozzle gave best results at a pressure of $0.3 \mathrm{MPa}$ with least coefficient of variation of 61.56 per cent. The discharge rate of nozzles increased with increasing operating pressure. The HCN/PB nozzle recorded minimum discharge rate at all operating pressure compared with other selected nozzles and found suitable for cotton crop. The droplet size of tested nozzles decreased with increase in pressure. The HCN/PB nozzle produces best droplet size within the range of 100 to $150 \mu \mathrm{m}$, good uniformity and the maximum percentage of volume of droplets at 100 to $200 \mu \mathrm{m}$. The swath width and spray angle of nozzles increased with the increase in pressure for all the four types of nozzles. The coefficient of variation in spray distribution was lower for HCN/PB nozzle followed by HCN/PD, $\mathrm{HCN} / \mathrm{PC}$ and highest for HCN/PE. 


\section{References}

Giles, D. K. and J. A. Comino. 1990. Droplet Size and Spray Pattern Characteristics of an Electronic Flow Controller for Spray Nozzles. J. Agric. Eng. Res., 47: 249-267.

Jayashree, G.C. 2013. Investigation on crop, machine and operational parameters towards development of a tractor operated target actuated sprayer. Unpublished Ph.D Thesis- Dept. of Farm Machinery, Tamil Nadu Agricultural University, Coimbatore.

Johnstone, N.R., P.T. Walkar and K.N. Huntington. 1972. Ultra low volume, hand operated mortised sprayers for insecticide application in citrus. Ins. Pest Contro, 14: 8-19

Senthilkumar. T., and V.J.F. Kumar 2007.
Evaluation of hydraulic energy nozzles suitable for orchard sprayin. Agricultural Mechanization in Asia, Africa and Latin America. 38(2), 13-17. Singh S K, S. Singh, V. Sharda and N Singh. 2006. Performance of different nozzles for tractor mounted sprayers. J Res Punjab agric Univ., 43(1): 44-49.

Tajuddin, A., 1995. Investigation on the effect of operational and atomizer parameters on the performance of battery powered spraying system. Unpublished Ph.D Thesis- Dept. of Farm Machinery, Tamil Nadu Agricultural University, Coimbatore.

Thronhill, E.W., and G.A. Mathews, 1995. Pesticide application equipment for use in agriculture vol.2. Mechanically powered equipment - FAO Agricultural Services Bulletin, 112/2.

\section{How to cite this article:}

Syed Imran, S. and Surendrakumar, A. 2018. Evaluation of Hydraulic Energy Nozzle Suitable for Low Velocity Air-Assisted Sprayer. Int.J.Curr.Microbiol.App.Sci. 7(01): 1398-1405. doi: https://doi.org/10.20546/ijcmas.2018.701.171 